\title{
Use of Computer Technology for the teaching of primary school mathematics
}

\author{
S. N. Dissanayake ${ }^{1 *}$, A.S. Karunananda ${ }^{2}$ and \\ G. D. Lekamge ${ }^{3}$ \\ ${ }^{1}$ Department of Mathematics and Computer Science, the Open University of \\ Sri Lanka \\ ${ }^{2}$ Faculty of Information Technology, University of Moratuwa \\ ${ }^{3}$ Department of Secondary and Tertiary Education, the Open University of \\ Sri Lanka
}

There is a rapid change in new technologies today than ever before. Among them, computer technology is the most wide spread technology. However, when new technologies are used in areas such as education, they must be done with a proper theoretical basis to match the discipline.

This paper describes the development of a computer based framework for the teaching of mathematics. The research study was carried out on sixty students in grade eight. The framework for designing the computer package was based on David Ausubel's Subsumption Theory, which falls under the cognitive theory of education. This theory was selected because mathematics deals with conceptual structures and abstract models. An intelligent framework, which enables expert system features with threelayer architecture, namely, visual level, conceptual level and abstract level has been postulated. The visual level of the framework supports the understanding through visual objects in the real world. The conceptual level promotes the understanding through concepts while the abstract level leads to abstract thinking, which is at the core of mathematics. Each level comprises modules for teaching and evaluation before going to the next level.

Students showed significant gains in their performance after using this computer package. The computer based framework identified in this study could be used as a generic framework to teach abstract mathematical concepts meaningfully at the primary school level.

\footnotetext{
* Correspondence should be addressed to Ms S. N. Dissanayake, Department of Mathematics and Computer Science, the Open University of Sri Lanka (email: shyamalidiss@yahoo.com).
} 


\section{Introduction}

A survey done on secondary education to study the key reasons for the downward trend of learning mathematics, revealed that at the early stages students are less familiar with fractions (Wijetilaka, 1992). The survey indicated that students have a very poor knowledge of

- distinguishing mixed fractions and common fractions

- conversion

- division by a fraction.

In view of this it is important to ensure correct learning of fractions at an early stage in our educational system. If this small error is not rectified at the lower grades it will affect not only the students but also adults at different times.

New Technologies are widely used in many day-to-day activities and have a tremendous impact on our lives. Among them computer technology is the most wide spread technology. However, when computer technology is used in areas such as education, it must be based on principles of teaching and learning.

In addressing the above, a framework for computer-based learning of mathematics was developed. For the development of the framework learning theories related to mathematics learning and Artificial Intelligence techniques were considered.

\section{Research Objectives:}

The overall objectives of this research study are to:

- $\quad$ Study learning theories related to mathematics learning.

- $\quad$ Develop a framework for computer-based learning of mathematics.

- $\quad$ Evaluate the approach using the framework developed. 


\section{Theoretical Framework}

This study is based on David Ausubel's Subsumption Theory (Ausubel, 1968) which states that "the most important single factor influencing learning is what the learner already knows, follow this and teach accordingly".

By exploiting Ausubel's Subsumption Theory, the following hypotheses were postulated in the following manner for the development of a computer-based system for mathematics. The hypotheses for this study are:

1. David Ausubel's theory can be exploited to develop an intelligent learning model.

2. This model can be developed as a generic framework for computer-based learning of mathematics.

3. The above framework of computer-based learning of mathematics can support problem solving ability in mathematics and abstract thinking.

\section{Approach}

The development of a framework for computer-based mathematics learning is based on the intelligent learning of Artificial Intelligence (Schuter, 1990 pp. 25) and the learning theories of education that support mathematics learning. Intelligent learning is the function of teaching that can be performed by a computer program where there will be interaction in both ways.

Learning theories are classified into three basic theories, namely the behaviorist theory, cognitive theory and the constructivist theory. Behaviorists argue that learning results in changes in the learner's behavior as a result of learning and focuses on the output of the learning process. Cognitivists believe that learning occurs when learners are able to add new concepts and ideas to the existing cognitive structure by recognizing a relationship between ideas that they already know and what they are learning and thereby focusing on the input of the learning process. Constructivists consider that all learners construct their own perspective of the world, through individual experiences and schema. Constructivism focuses on constructing the learner to problem solving in ambiguous situations. 


\section{S. Dissanayake et al.}

Since mathematics falls under cognitive theory of education, David Ausubel's Subsumption Theory has been selected for this study. This theory has been selected since mathematics deals with step by step procedures in conceptual structures and abstract models. Therefore what the learner already knows is very crucial for learning as stressed by Ausubel.

According to the literature available there is very limited research based on Ausubel's Subsumption Theory for the development of a computer-based learning system for mathematics. So this research study will investigate whether this learning approach has any impact on learning mathematics.

\section{The Design model}

By exploiting the above, an intelligent framework was designed. The three-layer architecture, namely, visual level, conceptual level and abstract level has been postulated to enable expert system features (Figure 1). The visual level facilitates the understanding through visual objects in the real world. The conceptual level helps the learner to understand through concepts while the abstract level leads to abstract thinking. Each level comprises modules for teaching followed by an evaluation before going on to the next level. A special feature of the system is that the levels are restricted, as going back in the process of manipulation from abstract level to visual level.

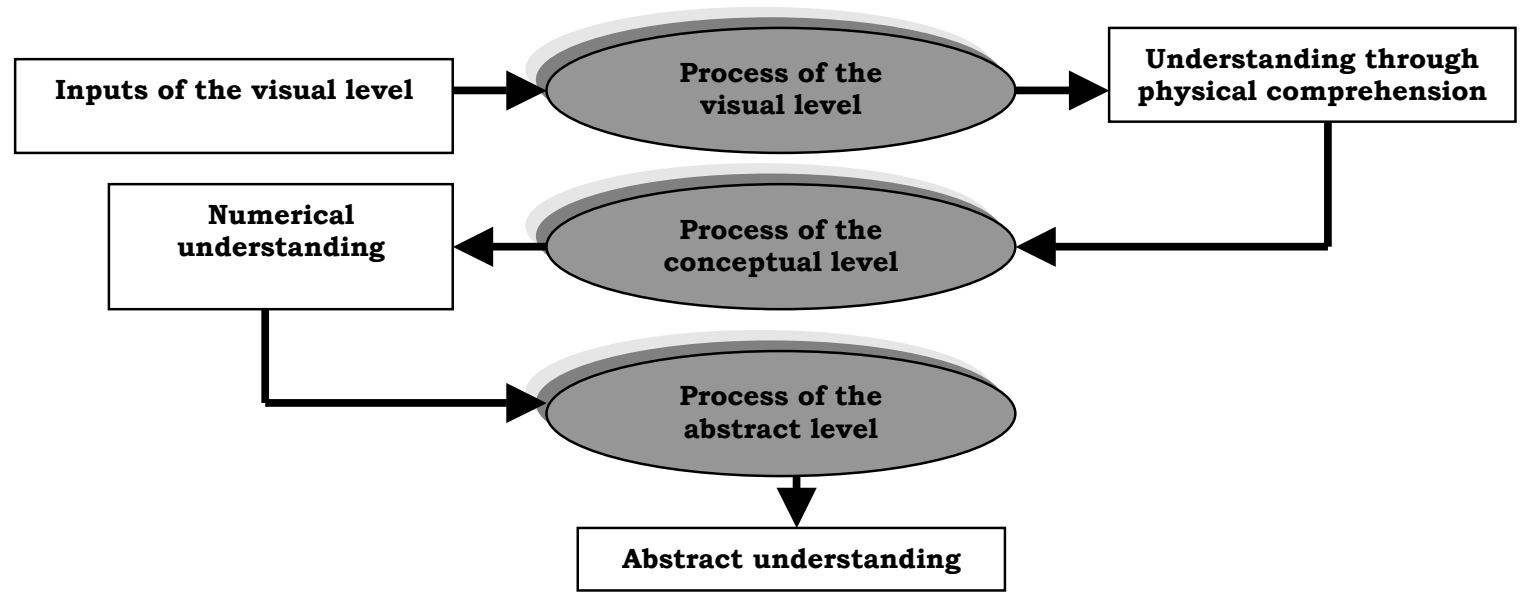

Figure 1. The Input-Process-Output scenario of the system 
The architecture of the proposed system is given in Figure 2.

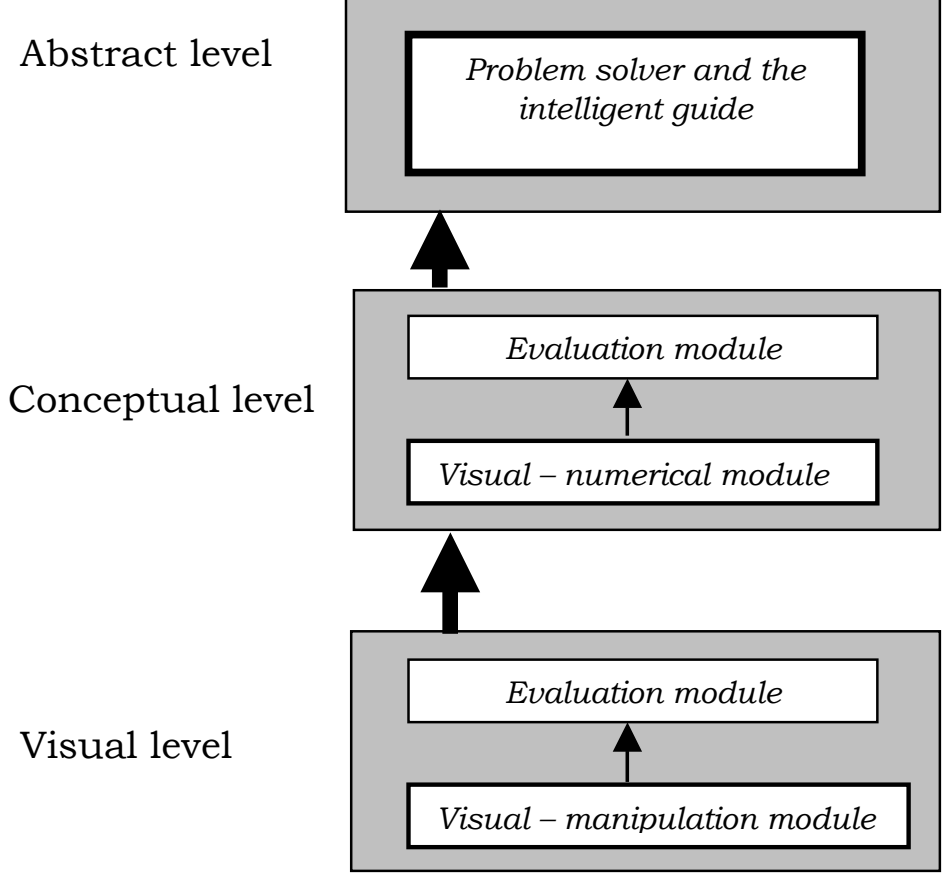

Figure 2. The architecture of the proposed system

\section{Visual level}

At the visual level there are two components. One being the visual manipulation module, where system-user interactions take place, and the other being the evaluation module. The main aim of this level is to introduce visuals regarding fractions to enable the user to understand the basic concept of mathematics.

Visual manipulation module

This is the initial stage where a user interacts with the system. In the visual manipulation module there are several models as in Figure 3. In each model the system forwards the questions in the form of visuals and the user gives the answer. There are several ways to answer these questions. One way is for the user to click on the answer buttons given. Another way is to highlight the visuals with the help of the mouse, or place the visual in a specific answer box provided. In all three cases, 


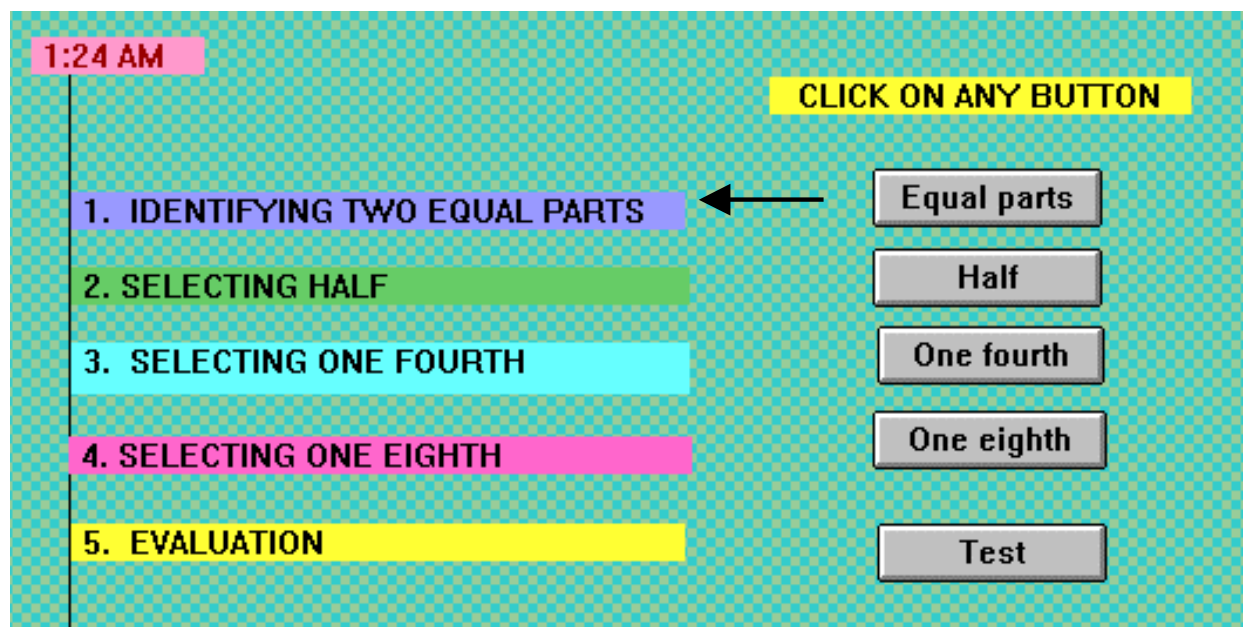

Figure 3. The main menu of the visual level

depending on the accuracy of the answer the system allows the user to proceed to the next model or attempt a re-trial. The user answers the questions with the knowledge acquired about the visuals. So, this level complies with exploiting of Ausubel's theory. According to the accuracy of the answer, the system allows the user to proceed or attempt again.

The manipulation of the model is illustrated by Figure 4.

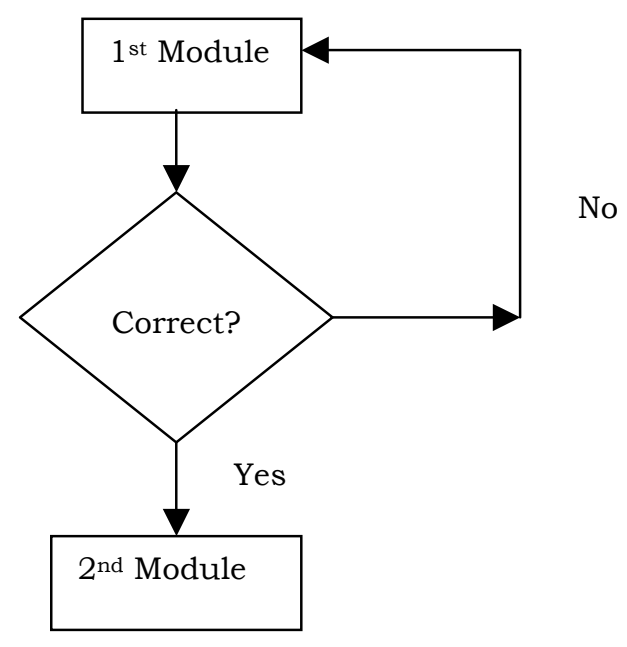

Figure 4. Study cycle among modules 
Evaluation module of the visual level

When the user completes the above module successfully, the user comes to the evaluation module, where the system informs the user of the progress of study. According to the answer given by the user the system instructs the user to follow the instructions at the next level or attempt. The evaluation is an intelligent feature of the system.

\section{Conceptual level}

The second level of the designed model is the conceptual level. Similar to the visual level there are two components one being the visualnumerical module and the other the evaluation module. Since the visual level is the known knowledge to the user at this stage this level also complies with Ausubel's Theory.

\section{Visual-numerical module}

At this stage the user has some knowledge about the concepts depicted by the visuals as outputs from the visual level. The second interaction with the system takes place at the visual-numerical module. Here the system poses questions in the form of visuals, and instructs the user to give the answer which gives the same sense that is given by numbers. The output will be the numerical understanding of the concept.

Evaluation module of the concept level

When the user completes the visual-numerical module successfully the user is directed to the evaluation module. At this stage the system poses a question and instructions on how to submit the answer. So at each point if the user gives an incorrect answer the system gives more guidance to the user to submit the correct answer. This procedure is continued until the final answer is obtained. Giving the accuracy of the answer and providing guidelines to the user are the intelligent features at this level.

\section{Abstract Level}

At the final or the abstract level, the main mechanism is to give knowledge of problem solving only with numbers. For this purpose there is a problem solver and an intelligent guide. 
The Problem solver and the intelligent guide

When a user reaches this level the necessary idea about a concept in mathematics is acquired. So at this final stage the system poses questions that involve problem solving only with numbers. The intelligent guide gives instructions to the user under the step by step procedure with the accuracy of the answer. If the user gives the correct answer, the intelligent guide will instruct the user to follow future models, otherwise, it will give the user a chance to attempt a re-trial. The feedback for answers and the instructions given to obtain the correct answer after completing the first attempt are the intelligent features of the intelligent guide at the abstract level. The final output is the ability to deal with any complicated problem in an abstract manner. When a user comes to this level the system restricts the user from going back in the process from abstract level to visual level because the main aim of the system is to deal with an abstract manner without using visual comprehension.

The study cycle attached to each level of the system is graphically shown in Figure 5.

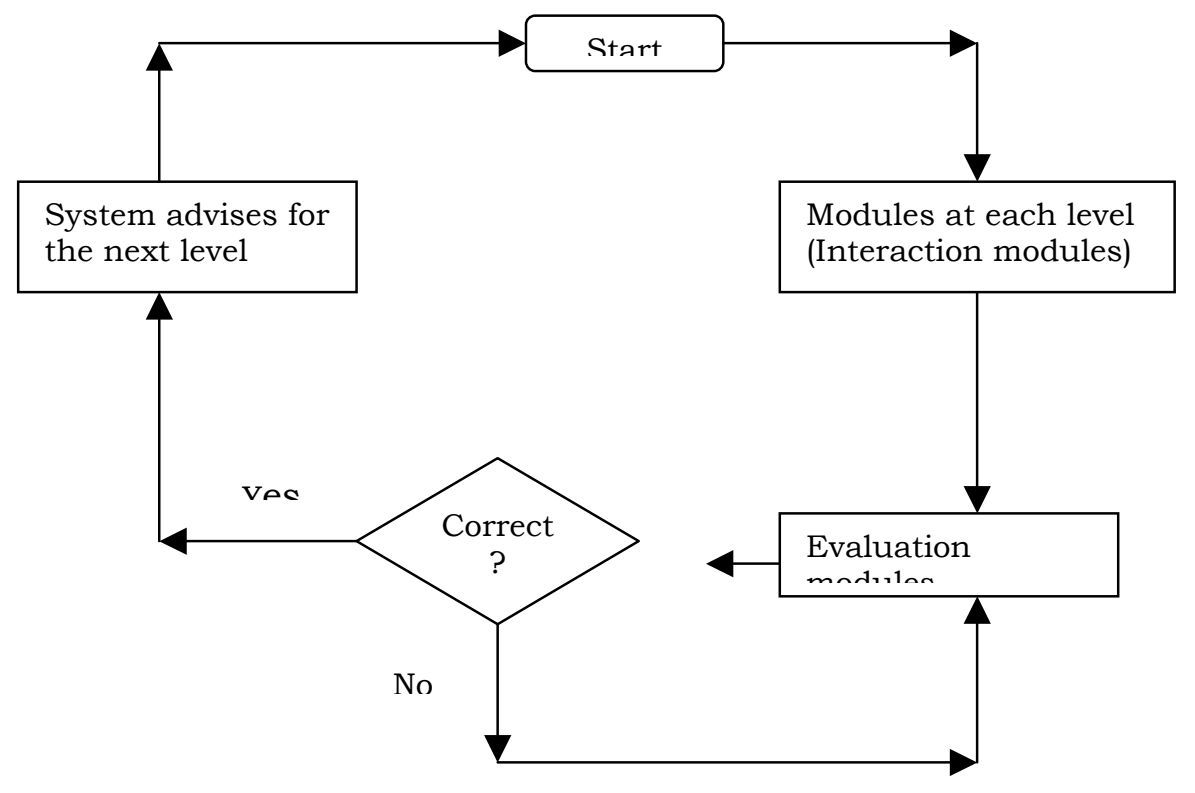

Figure 5. The study cycle behind each level 


\section{I mplementation of the system}

\section{Visual level}

After completing the visual manipulation module the evaluation module, evaluates the user by posing a question related to what the user has already learned (Figure 6). If the user clicks on the correct answer button the system allows the user to proceed to the next level, the conceptual level. If the user provides an incorrect answer the system explains the reasons for the incorrect answer and allows the user to try the question again. The indication of the accuracy of the answer and the instructions given to rectify the incorrect answer are the intelligent features of this module.
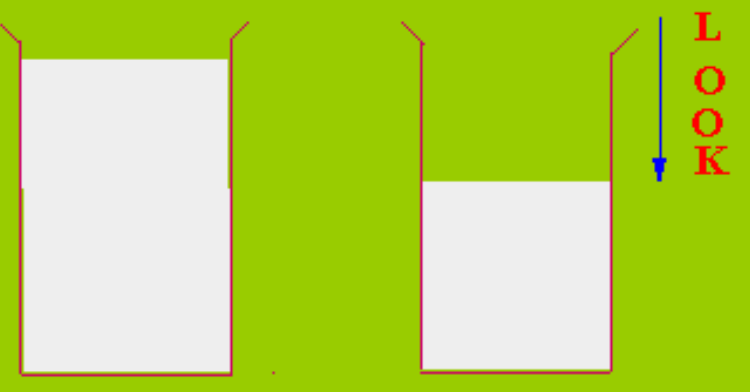

A qlass of milk

Figure 6. An evaluation module of the visual level

\section{Conceptual level}

The main aim of this level is to convert the visual ideas into numbers. This task will be carried out by the visual-numerical module and the evaluation is done by the evaluation module. These are the two main components at the conceptual level. The implementation procedure of the two modules are given below (Figure 7). 


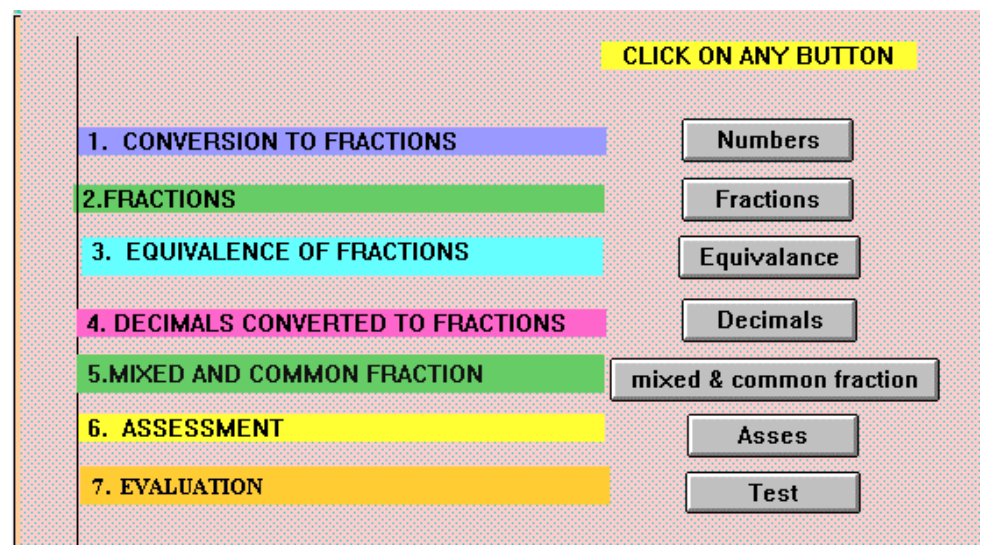

Figure 7. Main menu of the conceptual level

\section{Visual-numerical module}

At the initial stage the visual-numerical module gives a summary of the visuals that were in the visual level and a conversion to numbers. By this introduction the user will gain an idea of how the visuals are represented by numbers and the names given to them in the mathematical form (Figure 8). Then this module poses questions, to the user. To answer these questions the user has to insert the answer in the box provided with the help of the keys. According to the accuracy of the answer the user will come to the evaluation module, otherwise there will be a re-trial.

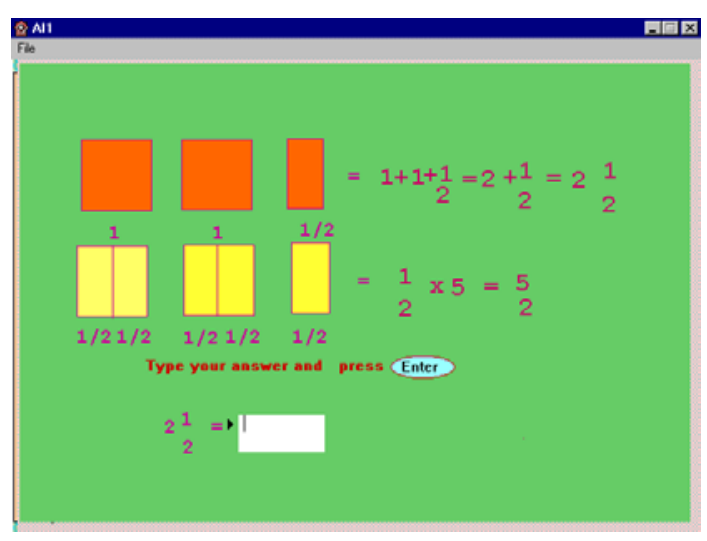

Figure 8. A module from the conceptual level 


\section{Evaluation module of the conceptual level}

The evaluation module evaluates the user by forwarding a question regarding the area that was under consideration by the above module. The user has to insert the answer in the box provided. If the answer is correct the evaluation module will instruct the user to follow the instructions at the next level, the abstract level. On the other hand if the answer is incorrect the user can try again. At the re-trial, when the new answer is given in the answer box the previous answer will be deleted automatically (Figure 9).

\section{Solve the problem}

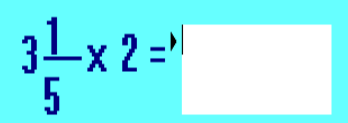

INSTRUCTIONS TO TYPE THE ANSWER:

1.Simplity the fraction.

2.Keep a space before and after the operator $(\mathrm{X})$.

3.Type the next value, then =

4.Type the answer in the box and press ENTER

Figure 9. Evaluation module of the conceptual level

\section{Abstract level}

When a user comes to this level most of the fundamentals that the user must gain at the visual level and the conceptual level are completed. At this stage the system will introduce the extensive problem solving procedure by the problem solver and help to solve the problem is given by the intelligent guide (Figure 10). At this level there will be only numbers and no visual aids. Another special feature is that when a user comes to this level the system will impose restrictions against going back in the process from abstract level to visual level. This is because the main aim is to improve the abstract thinking of the user when dealing with mathematics. 


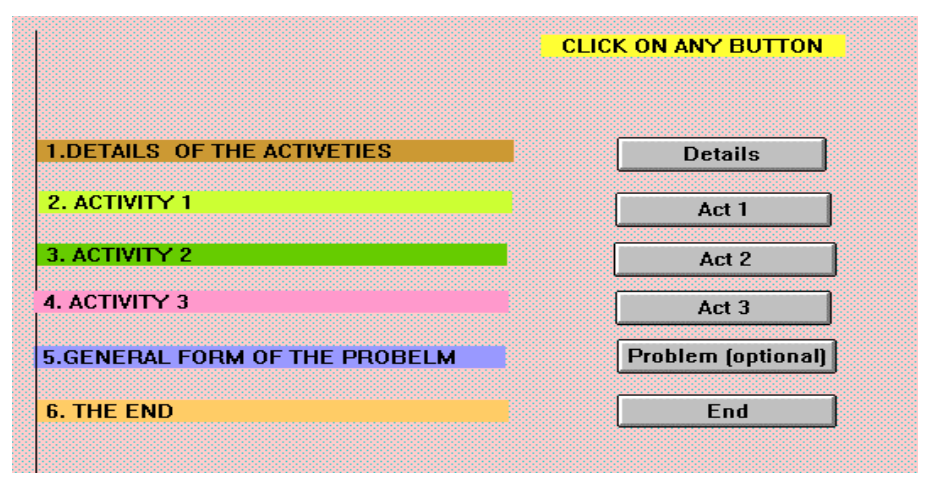

Figure 10. Main menu of the abstract level

\section{Problem solver}

The problem solver will introduce the most general problem regarding to some area of mathematics. Then with certain conditions it will be broken down into a number of activity models.

- $\quad$ The first activity will be the simplest form of the general problem.

- The second activity will be more complex than the first activity.

- The third activity will be the general form of the problem.

- $\quad$ So when the user completes the first activity and the second activity the user is fully aware of proceeding to the general form of the problem which will be the third activity.

Intelligent guide

The intelligent guide helps the user to carry out the activity models through a step by step procedure (Figure 11). According to the accuracy of the answer given by the user the intelligent guide will instruct the user to follow the next step or go for a re-trial. This will continue until the user obtains the final answer. 


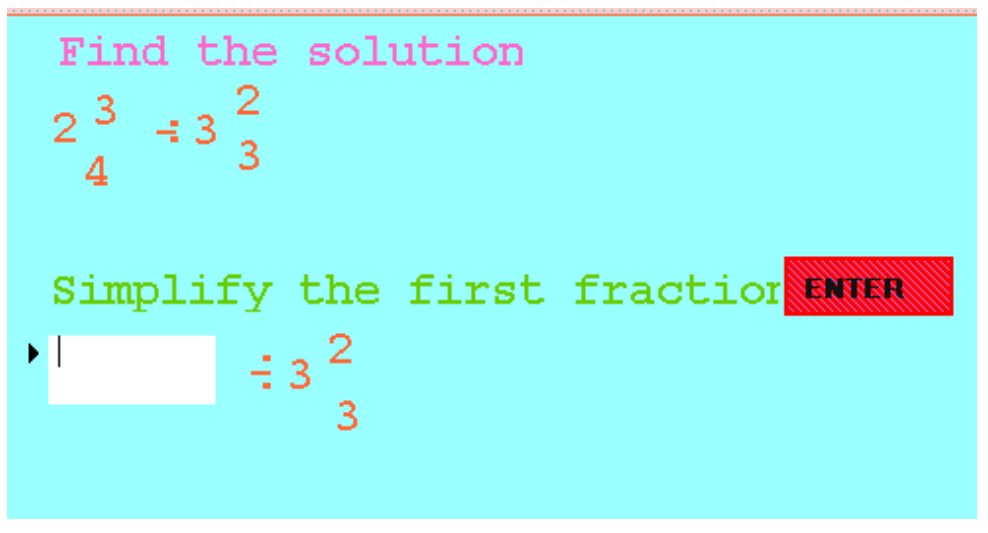

Figure 11. An evaluation module of the abstract level

\section{Method}

The target group was grade eight students and they were split into Group X and Group Y. The experiment control consists of three stages. These were named as stage 1 , stage 2 and stage 3 . The tests given to the students at the three stages were labeled as test 1 , test 2 and test 3 . At all three tests the time was recorded and marks were given for the steps taken to solve the problem.

\section{Assumptions made in the experiment setup}

The assumptions made in order to carry out the proposed experiment design are listed below.

- $\quad$ All students in the two groups are equally competent in using computers.

- The three tests given at the three stages are of equal standard.

- $\quad$ Each test paper contained four problems regarding division of fractions.

- $\quad$ Time duration is thirty minutes to workout each test paper.

- The time given to each group to use the system was one hour.

Stage 1: Groups $\mathrm{X}$ and $\mathrm{Y}$ were taught to solve problems regarding fractions by the traditional teaching methods. To test there pre knowledge about fractions test 1 was given to both groups. 
Stage 2: Group X was allowed to interact with the system and Group Y was not allowed to interact with the system. Both groups were retested with test 2 .

Stage 3: Group Y was given the opportunity to interact with the system. Then both groups were tested with test 3 . At this stage both groups had interacted with the system. The performance of the two groups were noted before and after using the system. The test papers given at the three stages are given in Appendix A. The three stages of the experiment above are summarized in the Table 1.

Table 1. Summary of the experiment

\begin{tabular}{|l|l|l|l|}
\hline $\begin{array}{l}\text { Test paper } \\
\text { No. }\end{array}$ & Group X & Group Y & Outcome \\
\hline Test paper 1 & $*$ & $*$ & $\begin{array}{l}\text { To test the pre- } \\
\text { knowledge. }\end{array}$ \\
\hline Test paper 2 & $\sqrt{ }$ & $*$ & $\begin{array}{l}\text { To observe the effect } \\
\text { on Group X. }\end{array}$ \\
\hline Test paper 3 & $\sqrt{ }$ & $\sqrt{ }$ & $\begin{array}{l}\text { To observe the effect } \\
\text { on Group Y. }\end{array}$ \\
\hline
\end{tabular}

*- Before interacting with the system.

$\sqrt{ }$ - After interacting with the system.

So by the performance of test 3 a measurable effect of the developed system with a comparison of performance at tests 1 and 2 (X performance) and also with tests 1 and 3 ( $\mathrm{Y}$ performance) can be obtained.

\section{Findings and Discussion}

Table 2 gives the summary of the scores of the two groups expressed as percentages. Considering the performance of the two groups after interacting with the system, Group X has an increase of 30\% (54.3$24.3)$ and Group $Y$ also has an increase of $30 \%(51.5-21.4)$ in problem solving ability regarding fractions. 
Table 2. Correct answers as percentages at each stage

\begin{tabular}{|l|l|l|l|}
\hline & $\begin{array}{l}\text { Stage 1: } \\
\text { Without using the } \\
\text { system }\end{array}$ & $\begin{array}{l}\text { Stage 2: } \\
\text { Group X used the } \\
\text { system \& Group } \\
\text { Y did not use the } \\
\text { system }\end{array}$ & $\begin{array}{l}\text { Both groups used } \\
\text { the system }\end{array}$ \\
\hline Group X & $24.3 \%$ & $52.6 \%$ & $54.3 \%$ \\
\hline Group Y & $21.4 \%$ & $21.4 \%$ & $51.5 \%$ \\
\hline
\end{tabular}

By the above comparison which is illustrated by Figures 13 and 14, it is clear that the student numbers have decreased in the mark range of 0-20 after interacting with the system. Similarly, taking into account other marks ranges such as 20-40 and 80-100 the student numbers have increased. Figure 13 represents the performance of the target groups as an intermediate stage.

Figure 12. The performance of students at stage 1

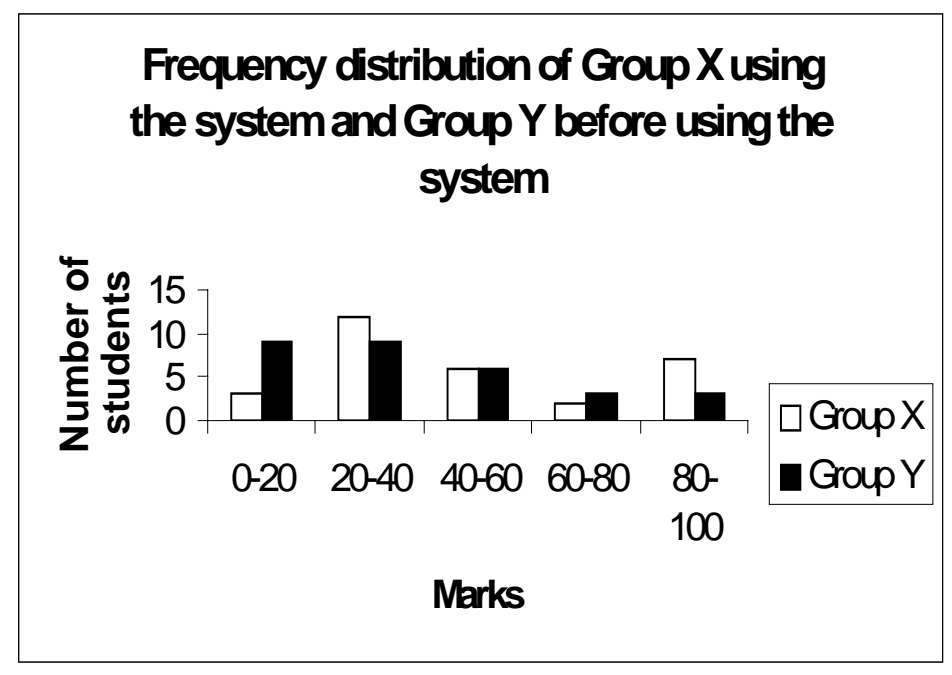

Figure 13. The performance of students at stage 2 


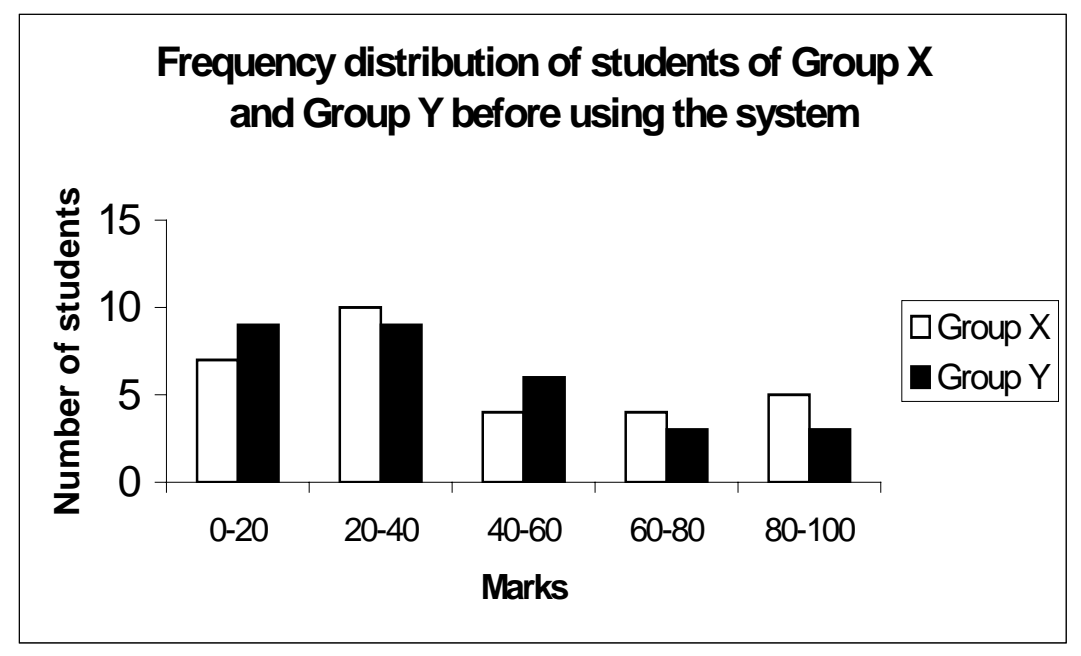

Figure 14. The performance of students at stage 3

After interacting with the system the student number in Group X within the mark range of $0-20$ has reduced by 4 . Two of the students have gained marks to enter the range of 20-40 and the other two students obtained marks to enter the range 40-60.

It was also noticed that two students who were earlier in the mark range of 60-80 have gained marks to enter the range 80-100.

Analyzing, the data of student numbers of Group Y after interacting with the system it is revealed that student numbers have reduced within the marks range of $0-20$ by 4 and have moved to the $29-40$ range, 40-60 range and 60-80 range respectively. The marks of one student of the 60-80 range has moved to $80-100$ range.

Another factor that was noticed from the data collected was that students who have scored 80-100 at the first stage have taken less time to complete the tests.

All these factors indicate that the students have gained better knowledge of how to solve problems regarding division of fractions using computer-based learning compared to the traditional learning methods used in schools.

If there were more multimedia features like sound and more animation, this system would have been more attractive to the students. It was 
revealed by the teachers that if the language used had been Sinhala it would have been more effective to the students as they are learning the subject in their mother tongue.

\section{References}

Ausubel, D., (1968) Learning Theories. Available online at: http://www.csuchico.edu/ ah24/ausubel.htm

Schutzer, D., (1990) Artificial Intelligence An Application-Oriented-Approach. New York: Nostrand Reinhold Company

Wijetilaka, R.N., (1992). The report of a survey done to study the difficult areas encountered in mathematics. Colombo: National Institute of Education. 
S. Dissanayake et al.

Appendix A- Test papers given at the three stages

Stage :1

Test paper: 1

Grade :

Time :

Solve the following.

1. $1 \frac{3}{5} \div \frac{2}{3}$

2. $\frac{3}{8} \div 2 \frac{1}{2}$

3. $2 \frac{1}{4} \div 1 \frac{2}{3}$

4. $\left(3 \frac{1}{3} \div 2 \frac{1}{6}\right) \times \frac{1}{4}$ 


\section{Appendix B- Test papers given at the three stages}

Stage :2

Test paper:2

Grade :

Time :

Solve the following.

1. $3 \frac{1}{4} \div \frac{3}{4}$

2. $\frac{2}{3} \div 2 \frac{1}{5}$

3. $7 \frac{1}{2} \div 1 \frac{2}{3}$

4. $\left(2 \frac{1}{4} \div \frac{3}{14}\right) \times 2 \frac{1}{7}$ 
S. Dissanayake et al.

Appendix C- Test papers given at the three stages

Stage :3

Test paper:3

Grade :

Time :

Solve the following.

1. $2 \frac{1}{2} \div \frac{3}{5}$

2. $\frac{4}{9} \div 3 \frac{1}{3}$

3. $4 \frac{1}{5} \div 1 \frac{3}{4}$

4. $\left(7 \frac{1}{2} \div 1 \frac{1}{4}\right) \times \frac{1}{12}$ 